\title{
Oral Health-related Quality of Life and Periodontal and Dental Health Status in Iranian Hemodialysis Patients
}

\author{
${ }^{1}$ Arefe Hajian-Tilaki, ${ }^{2}$ Farshid Oliae, ${ }^{3}$ Niloofar Jenabian, ${ }^{4}$ Karimollah Hajian-Tilaki, ${ }^{5}$ Mina Motallebnejad
}

\begin{abstract}
Aim: The aim of this study was to evaluate oral health status and oral health related quality of life (OHRQoL) in Iranian patients undergoing hemodialysis.

Materials and methods: In this cross-sectional study 145 (95 dentate and 50 edentulous) patients undergoing hemodialysis participated. Demographic information, laboratory findings and dental health status was recorded by a standard form. Oral hygiene status was obtained by simplified oral hygiene index $(\mathrm{OHI}-\mathrm{S})$ and oral health was evaluated by decay missing filling teeth (DMFT) index, plaque index (PLI) and periodontal disease index. Oral health related quality of life was determined by means of short form oral health impact profile (OHIP-14) and general oral health assessment index (GOHAI).
\end{abstract}

Results: The mean $( \pm$ SD) DMFT, PLI and PDI were $15.47 \pm$ $7.85,2.03 \pm 0.95,4.09 \pm 1.31$ respectively. OHI-S was good in $7(7.4 \%)$, fair $25(26.6 \%)$ and poor in $38(26.6 \%)$ of patients. The mean OHIP-14 and GOHAI scores were $31.32 \pm 12.53$ and $29.07 \pm 8.5$ respectively. The self-perceived oral health of $58(40 \%)$ was good, $49(33.8 \%)$ was fair and $38(26.2 \%)$ was poor. Patients with higher scores for the questionnaires had significantly worst self-rated oral health. Besides, there was a significant positive correlation between dental and periodontal variables with OHIP-14 and GOHAI scores.

Conclusion: Hemodialysis patients had a poor oral hygiene and periodontal status, weak attitudes and negligence toward oral health but they were satisfied of their oral health condition and their OHRQoL was approximately good. Therefor it should be communications between nephrologists and oral health care professionals for promoting the oral health status of the patients.

Clinical significance: The findings high light the need of comprehensive oral examinations including periodontal therapy,

\footnotetext{
${ }^{1}$ Dental Student, ${ }^{2}$ Assistant Professor, ${ }^{3,5}$ Associate Professor ${ }^{4}$ Professor

${ }^{1,5}$ Department of Oral Medicine, Babol University of Medical Sciences, Mazandaran, Iran
}

${ }^{2}$ Department of Nephrology, Shahid Behashti Hospital, Babol University of Medical Sciences, Mazandaran, Iran

${ }^{3}$ Department of Periodontology and Implantology, Babol University of Medical Sciences, Mazandaran, Iran

${ }^{4}$ Department of Biostatistics and Epidemiology, Babol University of Medical Sciences, Mazandaran, Iran

Corresponding Author: Mina Motallebnejad, Associate Professor, Department of Oral Medicine, Babol University of Medical Sciences, Mazandaran, Iran, Phone: 989111114191 e-mail: mmotallebnejad@yahoo.com restorative treatment, preventive dental treatment and follow-up care in the hemodialysis patients.

Keywords: Chronic renal failure, Oral health related quality of life, Hemodialysis, Oral health, Periodontal disease, Dental health.

How to cite this article: Hajian-Tilaki A, Oliae F, Jenabian N, Hajian-Tilaki K, Motallebnejad M. Oral Health-related Quality of Life and Periodontal and Dental Health Status in Iranian Hemodialysis Patients. J Contemp Dent Pract 2014;15(4):482-490.

Source of support: Nil

Conflict of interest: None declared

\section{INTRODUCTION}

Chronic renal failure (CRF) is defined as a disease which is caused by irreversible reduction in the number of functional nephrons. ${ }^{1}$ Diabetes mellitus, glomerulonephritis and chronic hypertension are some of the main causes of this disease. ${ }^{1,2}$ The incidence of patients with CRF is increased in worldwide. ${ }^{2,3}$ Today, individuals with CRF are usually treated by hemodialysis (HD) for several times per week. Undergoing HD three times a week, will maintain the balance of fluid and electrolyte and will eliminate the waste products from the body. ${ }^{4}$ Due to the advances in the science and proper treatment, the survival rate among HD patients has increased. However, new problems including concerns of oral health, oral hygiene, periodontal status and the effect of oral health on quality of life has focused the attention of oral health professionals in the past few years. The common oral manifestations of these patients are dry mouth, taste change, malodor, gingivitis, dental calculus, dental caries and alteration in salivary composition and flow rate. ${ }^{2,5,6}$

According to the fact that quality of life $(\mathrm{QoL})$ is specifically related with health and disease, thus health related quality of life (HRQoL), is a multi-dimensional concept. ${ }^{7}$ One of the aspects of HRQoL is oral health related quality of life (OHRQoL). ${ }^{7}$ Oral health status could have a physical and psychological influence on the individuals life. It could simultaneously affect the pleasure of the individuals life, because of the role of oral conditions on speech, chewing, taste and swallowing, and in the social domains on the appearance and self-confident of the individuals. ${ }^{8}$

There are different questionnaires for assessing OHRQoL, among these instruments the short version of 
oral health impact profile (OHIP-14) and the general oral health assessment index (GOHAI) are the most widely used. They were initially developed in English-speaking countries (USA, Australia), ${ }^{8-11}$ and were translated and validated in several languages. ${ }^{12-16}$ Recently, GOHAI and OHIP-14 have been translated into Persian and its reliability and validity is acceptable for using it in Persian communities. ${ }^{17,18}$ OHIP-14 was developed by Slade in 1997 and its reliability and validity is approved. ${ }^{10}$ This questionnaire has two items for 7 dimensions. These seven dimensions consist of: functional limitation, physical pain, psychological discomfort, physical disability, psychological disability, social disability and handicap. ${ }^{9,10}$ GOHAI (previously known as the Geriatric Oral Health Assessment Index), has 12 items and evaluates three dimensions which are physical function, pain and discomfort and psychosocial function. ${ }^{11,19}$

Even though, there are several studies which evaluated, oral health and the periodontal status of HD patients in other countries and in different parts of Iran, but the relationship between hemodialysis treatment and periodontal indices and decay missing filling teeth (DMFT) scores showed conflicting findings in different societies. ${ }^{20-33}$ Some investigations reported that the prevalence of carries were lower among children and adults with $\mathrm{CRF},{ }^{20-24}$ while there are also other investigations reporting similar ${ }^{5}$ or higher DMFT index scores. ${ }^{25,26}$ Furthermore, periodontal diseases are a group of inflammatory diseases of the supporting tissues of the dentition. Chen et al reported, $58.9 \%$ of renal failure individuals demonstrated moderate to severe periodontitis. ${ }^{27}$ Although, there are different results reported for the periodontal status of these patients, some investigations demonstrated a positive relationship between periodontal diseases and the duration of the dialysis treatment, however; this association has not been found in other studies. ${ }^{25,28-33}$ As a result, the hemodialysis therapy and the complex medical conditions of subjects could affect the periodontal status and the dental and oral health of this group of patients. The patient dissatisfaction of its oral conditions, could have an influence on the different aspects of oral function, social status and the appearance. These conditions could cause patients dissatisfaction of its QoL that is related to oral health. According to our knowledge there are very limited studies in the world which evaluated the OHRQoL in the patients undergoing hemodialysis, and there is not sufficient information in this context. Hence, the aim of this study was to determine the dental and periodontal health status, the self-perceived oral health, attitude toward oral health and the effect of oral health on quality of life in the hemodialysis patients in Babol.

\section{MATERIALS AND METHODS}

In this cross-sectional study, all of the hemodialysis patients referring to Hemodialysis Center of Shahid Beheshti
Hospital (Babol, Iran) were enrolled. The patients which referred transitory were excluded of our study. One hundred and seventy patients undergoing dialysis regardless of the duration of hemodialysis were included in the study. Among these, 25 were excluded because of their unwilling or the lack of ability for participating in the study. Totally, 145 patients $(85.29 \%)$ took part in the study. The examination and interview was performed between 9th and 23th of July, 2013 by a dentist. The study protocol was approved by the Medical Ethics Committee of Babol University of Medical Sciences. Prior to the examination and filling the questioners, an informed consent was obtained by all the patients. Each participant underwent an intraoral examination by using mouth mirror, an explorer and a periodontal probe with William's markings. Thus, for the edentulous patients undergoing hemodialysis, just the questioners were completed and the dental and periodontal parameters and indices were not performed due to the edentulous condition.

The participants age, sex, smoking status and alcohol consumption, duration of hemodialysis therapy, the presents of infectious disease (hepatitis, HIV), Diabetic or Non diabetic main cause of hemodialysis, presents of prostheses, experiencing a sensation of dry mouth, bad taste or malodor mouth and the time of last dental visit were recorded in a standard form. In addition, for measuring self-perceived oral health the patients were asked to describe their oral health status as good, fair or poor. For evaluating the periodontal status, plaque index according to Silness and Loe (PLI), and periodontal disease index (PDI) were calculated by using Ram-fjord index tooth (Max right first molar, max left central, max left premolar, man left first molar, man right central, man right premolar). For examining the oral health status simplified oral hygiene index (OHI-S) by green and Vermillion 1964 and DMFT index were noted. OHI-S was calculated by using six index teeth (Max right first molar, max right central, max left first molar, man left first molar, man left central and man right first molar). In the case of missing teeth, the adjacent teeth and in case of missing the adjacent teeth, the opposite teeth were evaluated. The DMFT index was obtained as the sum of decay (D), missing (M) and filling (F) teeth, according to the criterion suggested by World Health Organization (WHO). ${ }^{34}$ In addition, for each patient we recorded some laboratory findings such as blood urea nitrogen (BUN) and creatinine $(\mathrm{Cr})$ which were taken 1 month before the clinical examination.

The Persian version of two standard questionnaires (OHIP-14 and GOHAI) were used in this investigation to evaluate the OHRQoL witch their reliability and validity are acceptable for using it in Persian communities. ${ }^{18,19}$ For those who were illiterate or were not able to complete the questionnaires because of their physical problem, the 
questions were read exactly by the examiner and the answers were noted. In the OHIP-14 responses were scored on a scale ranging from 1 to 5 . $(1=$ never, $2=$ seldom, $3=$ sometimes, $4=$ often and $5=$ very often) and it was also based on a 5 point scale for GOHAI. $(1=$ never, $2=$ seldom, $3=$ sometimes, $4=$ often and $5=$ always).

The statistical analysis was performed by using Statistical Package for the Social Science software version 18.0 (SPSS.18.0). Two methods were used for calculating OHIP-14 and GOHAI scores: additive (ADD) and simple count (SC). Additive scores were obtained by summing the response codes of 14 items for OHIP-14 and 12 items for GOHAI (after reversing the coding of item 3, 5 and 7 which were three positively worded items). Therefore, OHIP-14 and GOHAI scores ranged from 14 to 70 and 12 to 60 respectively with a lower score indicating better OHRQoL. Due to the possibility that some participants would not be able to make different between the 5 responds, the SC scoring method was assessed. In SC scores, responds like never, seldom, or sometimes get one-point and responses such as often or very often/always get two-points. Using this approach, SC scores ranges from 0 to 12 and 0 to 14 for the SC-GOHAI and the SC-OHIP-14 respectively with a lower score indicating a poorer OHRQoL. In statistical analysis, we used descriptive statistics included (means, standard deviations and percent) and nonparametric statistical tests. We used Mann-Whitney (Wilcoxon test) to analyze the difference between the mean values of the two groups regarding clinical parameters, Kruskal-Wallis one way analysis of variance was conducted to compare in more than two groups. A p-value less than 0.05 was considered to be significant in all tests. Person correlation coefficients were applied in determining the association between dental index and OHRQoL scores and also the correlation between the scores of the two questionnaires. In addition, for evaluating the internal consistency of responding items of each questionnaire the Cronbach's alpha was determined as a reliability measurement. Furthermore, to determine the effect of the duration of hemodialysis on periodontal status, oral and dental health and OHRQoL, the hemodialysis group was further divided into two subgroups: (1) those who had been on renal dialysis for $<24$ months, (2) those who had been on renal dialysis for $\geq 24$ months. Also, the patients were divided into three age groups: $(1)<40$ years, (2) 40 to 59 years $(3) \geq 60$ years.

\section{RESULTS}

A total of 145 hemodialysis patients who agreed to participate in this study, there were 77 males $(53.1 \%)$ and 68 females $(63.9 \%)$. The mean age $( \pm \mathrm{SD})$ of the patients was $58.17 \pm 17.76$ years ( 19 to 89 years). The length of time since participants had been diagnosed as having CRF ranged from 2 to 244 months and the mean duration of hemodialysis was $49.33 \pm 46.99$ months. One hundred and twenty $(82.8 \%)$ were nonsmoker, 17 (11.7\%) were former smokers, 8 (5.5\%) were smokers, also $142(97.9 \%)$ subjects had no history of alcohol consumption. In 54 patients (32\%) diabetes was the main cause of terminal renal failure. Besides $11(7.6 \%)$ had hepatitis and no one had HIV. In addition, 65 (44.8\%) had some kinds of prosthesis, among these 50 (34.5\%) had complete denture, $12(8.3 \%)$ had removable partial denture (RPD) and $3(2.1 \%)$ had fixed partial denture (FPD) and no one had implant supported prosthesis. Among those who had complete prosthesis $26(52 \%)$ were men and $24(48 \%)$ were women and their mean age was $70.56 \pm 11.41$ (39 to 89). In $113(77.9 \%)$ subjects, the last dental visit was more than 2 years prior to the interview. Complains of dry mouth, taste change and malodor were presented in $75(51.7 \%), 51$ (35.2\%), 58 (40\%) of the patients respectively. The mean BUN and Cr level was $73.86 \pm 24$ and $11.74 \pm 30.24 \mathrm{mg} / \mathrm{dl}$ relatively. The mean BUN and Cr was $75.87 \pm 24.24 \mathrm{mg} /$ $\mathrm{dl}$ and $13.78 \pm 24.37 \mathrm{mg} / \mathrm{dl}$ in men and $71.54 \pm 22.56$ $\mathrm{mg} / \mathrm{dl}$ and $9.39 \pm 13.88 \mathrm{mg} / \mathrm{dl}$ in women respectively. Although the mean of the BUN and the $\mathrm{Cr}$ level was higher in men, the different was not statistically significant, $[p=0.26$ (for BUN) and $\mathrm{p}=0.21$ (for $\mathrm{Cr}$ )]. The mean of BUN in patients who complained of malodor was $78.88 \pm 26.19 \mathrm{mg} / \mathrm{dl}$ and in patients who did have malodor sensation was 70.49 $\pm 22.65 \mathrm{mg} / \mathrm{dl}(\mathrm{p}=0.038)$.

The dental and periodontal evaluations were performed on 95 of 145 participants who were dentate. The average of the DMFT score was $15.47 \pm 7.85$ ( 0 to 28 ). The mean of the decayed, missed and filled tooth were $18 \pm 6.48,24 \pm 7.71$, $16 \pm 1.28$ respectively. Among the periodontal parameters, the mean PLI and PDI in the patients were $2.03 \pm 0.95$ and $4.09 \pm 1.32$ respectively. The results of the OHI-S revealed that among the 95 subjects, 7 (7.4\%) had good oral hygiene, $25(26.6 \%)$ had fair oral hygiene and $63(66.3 \%)$ had poor oral hygiene.

Table 1 shows the dental and periodontal indices and OHI-S of the individuals according to age, sex and hemodialysis duration. Except the decay and filled tooth, other items had a significant relationship with age $(p<0.001)$. As age increases, DMFT score gets higher and the oral health and the periodontal status deteriorates. According to gender, the periodontal indices and DMFT tended to be higher in men than women but did not reached at significant level. With respect to duration of hemodialysis, there were no significant differences between periodontal indexes, DMFT and OHI-S with the hemodialysis duration. 
Out of 95 dentate subjects, the mean DMFT score was significantly $(\mathrm{p}=0.014)$ higher in the diabetic main cause group (18.16 \pm 6.19$)$ in compare with the non-diabetic group $(14.17 \pm 8.28)$. The mean of the missing teeth was $10.06 \pm$ 7.30 in the diabetic group in compare with $6.56 \pm 6.51$ in the non-diabetic group which presents the fact that patients with diabetes have significantly less number of teeth $(p=0.012)$. The mean PLI score in diabetic and non-diabetic patients was $2.25 \pm 0.89$ and $1.93 \pm 0.97$ respectively $(p=0.08)$ and the mean PDI score in diabetic and non-diabetic patients was respectively $4.37 \pm 1.25$ and $3.96 \pm 1.35(\mathrm{p}=0.16)$.

The relation of different oral complains based on the present of diabetes, duration of hemodialysis and the dentition status is shown in Table 2 . There was no statistically significant different between these complains with the dentition status, duration of hemodialysis and the diabetic main cause of the disease $(p>0.05)$.

All 145 participants under hemodialysis filled out all of the items in the questionnaires. The mean score for OHIP-
14-ADD, OHIP-14-SC, GOHAI-ADD and GOHAI-SC was $31.32 \pm 12.53(14-68), 1.92 \pm 3.36(0-13), 29.07 \pm 8.5(14-$ $50)$ and $2.54 \pm 2.48(0-10)$ respectively. Tables 3 and 4 show the frequency of subjects responding for GOHAI and OHIP14 items on the basis of ADD and SC calculation method. The internal reliability (Cronbach's Alpha) was $96.2 \%$ for OHIP-14-ADD, $92.4 \%$ for OHIP-14-SC, $85.0 \%$ for GOHAIADD and $76.8 \%$ for GOHAI-SC. The correlation between OHIP-14-ADD and GOHAI-ADD was $0.870(\mathrm{p}=0.001)$ and it was $0.804(p=0.001)$ for OHIP-14-SC and GOHAISC. Although Pearson correlation coefficient was 0.830 $(\mathrm{p}=0.001)$ between OHIP-14-ADD and OHIP-14-SC, and it was $0.864(p=0.001)$ between GOHAI-ADD and GOHAISC. On the basis of SC scores, the percentage of individuals who responded often and always/very often to each item ranged from 5.5 to $24.1 \%$ for OHIP-14 and 1.4 to $40.0 \%$ for GOHAI, which indicates that GOHAI had a wider scale.

Among 145 patients who respond to the self-rated oral health question, $58(40.0 \%)$ rated good, $49(33.8 \%)$ rated

Table 1: Dental and periodontal parameters (mean \pm SD) and OHI-S of patients undergoing dialysis according to age, sex and duration of dialysis

\begin{tabular}{|c|c|c|c|c|c|c|c|c|c|c|}
\hline & \multirow[t]{2}{*}{ Variables } & \multicolumn{2}{|c|}{ Periodontal parameters } & \multicolumn{2}{|c|}{ Dental } & \multicolumn{2}{|c|}{ Parameters } & \multicolumn{3}{|c|}{$\mathrm{OHI}-\mathrm{S}$} \\
\hline & & $\begin{array}{l}P L I \\
\text { (mean } \pm \\
S D)\end{array}$ & $\begin{array}{l}P D I \\
\text { (mean } \pm \\
S D)\end{array}$ & $\begin{array}{l}\text { Decay } \\
\text { (mean } \pm \\
S D)\end{array}$ & $\begin{array}{l}\text { Missing } \\
\text { (mean } \pm \\
S D)\end{array}$ & $\begin{array}{l}\text { Filling } \\
\text { (mean } \pm \\
S D)\end{array}$ & $\begin{array}{l}\text { DMFT score } \\
\text { (mean } \pm \\
S D)\end{array}$ & $\begin{array}{l}\text { Good } \\
n(\%)\end{array}$ & Fair $n(\%)$ & $\begin{array}{l}\text { Poor } \\
n(\%)\end{array}$ \\
\hline & $\begin{array}{l}<40 \text { years } \\
n=25\end{array}$ & $1.31 \pm 0.73$ & $2.76 \pm 1.14$ & $5.44 \pm 3.97$ & $2.32 \pm 2.46$ & $1.32 \pm 2.44$ & $9.08 \pm 5.13$ & $3(12.0)$ & $12(48.0)$ & $10(40.0)$ \\
\hline \multirow[t]{3}{*}{ Age } & $\begin{array}{l}40-59 \text { years } \\
n=38\end{array}$ & $1.99 \pm 0.97$ & $4.19 \pm 1.13$ & $6.26 \pm 3.72$ & $7.21 \pm 5.97$ & $1.97 \pm 4.20$ & $15.44 \pm 7.27$ & $4(10.5)$ & $9(23.7)$ & $25(65.8)$ \\
\hline & $\begin{array}{l}\geq 60 \text { years } \\
\mathrm{n}=32\end{array}$ & $2.65 \pm 0.61$ & $5.03 \pm 0.68$ & $7.56 \pm 4.19$ & $12.5 \pm 7.16$ & $0.44 \pm 1.79$ & $20.50 \pm 6.67$ & $0(0.0)$ & $4(12.5)$ & $28(87.5)$ \\
\hline & $p$-value & 0.001 & 0.001 & 0.12 & 0.001 & 0.13 & 0.001 & & 0.004 & \\
\hline \multirow[t]{3}{*}{ Sex } & $\begin{array}{l}\text { Male } \\
(n=51) \\
(\text { mean } \pm S D)\end{array}$ & $2.18 \pm 0.8$ & $4.37 \pm 1.09$ & $6.72 \pm 4.28$ & $7.92 \pm 6.94$ & $1.57 \pm 3.75$ & $16.22 \pm 8.18$ & $3(5.9)$ & $11(21.6)$ & $37(72.5)$ \\
\hline & $\begin{array}{l}\text { Female } \\
(n=44) \\
(\text { mean } \pm S D)\end{array}$ & $1.86 \pm 1.04$ & $3.78 \pm 1.50$ & $6.20 \pm 3.66$ & $7.45 \pm 7.00$ & $0.95 \pm 2.28$ & $14.61 \pm 7.47$ & $4(9.1)$ & $14(31.8)$ & $26(59.1)$ \\
\hline & $p$-value & 0.19 & 0.07 & 0.72 & 0.68 & 0.46 & 0.32 & & 0.38 & \\
\hline Dialysis & $\begin{array}{l}<24 \text { month } \\
(\mathrm{n}=37)\end{array}$ & $1.96 \pm 0.99$ & $3.98 \pm 1.27$ & $6.27 \pm 4.17$ & $7.21 \pm 6.37$ & $2.65 \pm 4.53$ & $16.13 \pm 7.49$ & $4(10.8)$ & $9(24.3)$ & $24(64.9)$ \\
\hline Duration & $\begin{array}{l}\geq 24 \text { month } \\
(\mathrm{n}=58)\end{array}$ & $2.07 \pm 0.92$ & $4.18 \pm 1.37$ & $6.62 \pm 3.91$ & $8.01 \pm 7.32$ & $0.41 \pm 1.22$ & $15.05 \pm 8.11$ & $3(5.2)$ & $16(27.6)$ & $39(67.2)$ \\
\hline & $p$-value & 0.57 & 0.30 & 0.98 & 0.76 & 0.004 & 0.51 & & 0.58 & \\
\hline
\end{tabular}

OHI-S indicates simplified oral hygiene index; PLI: Plaque index; PDI: Periodontal disease index; DMFT: Decay missing filling tooth

Table 2: The presented of complaints, such as dry mouth, taste change and malodor according to the dialysis duration, dentition and diabetic status

\begin{tabular}{llllllll}
\hline Variables & & $\begin{array}{l}\text { Dry } \\
\text { mouth }\end{array}$ & $p$-value & Taste change & $p$-value & Malodor & $p$-value \\
\hline Dentition & Dentate $(\mathrm{n}=95)$ & $45(47.4)$ & 0.15 & $30(31.6)$ & 0.21 & $37(38.9)$ & 0.72 \\
& Edentulous $(\mathrm{n}=50)$ & $30(60.0)$ & & $21(42.0)$ & & $21(42.0)$ & \\
Dialysis & $<24$ month $(\mathrm{n}=47)$ & $23(48.9)$ & 0.64 & $17(36.2)$ & 0.86 & $20(42.6)$ & 0.66 \\
Duration & $\geq 24$ month $(\mathrm{n}=98)$ & $52(53.1)$ & & $34(34.7)$ & & $38(38.8)$ & \\
Diabetic & Yes $(\mathrm{n}=54)$ & $33(61.1)$ & 0.81 & $24(44.4)$ & 0.72 & $27(50.0)$ & 0.06 \\
Cause & No $(\mathrm{n}=91)$ & $42(46.2)$ & & $27(29.7)$ & & $31(34.1)$ & \\
\hline
\end{tabular}


fair and $38(26.2 \%)$ rated as poor, however the differences in the two genders were not significant $(p=0.08)$ but the number of missing teeth increased significantly as perceived oral health decreased $(\mathrm{p}=0.001)$.

Table 5 shows OHIP-14 and GOHAI scores with respect to sex, age group, duration of hemodialysis, OHI-S, selfrating of oral health, dry mouth, taste change, halitosis, diabetes. No statistically significant relation was found between the questionnaires scores and age, sex and the hemodialysis duration $(p>0.05)$ but OHIP-14 and GOHAI scores were significantly higher in patients with poor OHI-S. Although patients with higher scores for the questionaires had significantly worst self-rated oral health, and more oral manifestations. There was a significant correlation between the dental and periodontal avariables, and OHIP-14 and GOHAI results for both ADD and SC calculations (Table 6) Though, there was no correlation between duration of hemodialysis and OHIP-14 $(\mathrm{r}=0.028, \mathrm{p}=0.74)$ and GOHAI $(\mathrm{r}=0.076, \mathrm{p}=0.36)$ results.

\section{DISCUSSION}

In the present study, OHRQoL was evaluated in 145 subjects undergoing hemodialysis and periodontal and dental health of 95 dentate individuals were examined with the minimal number of indices. According to the present investigation, patients had high dental and periodontal indices which was not related to duration of hemodialysis treatment. Also, hemodialysis treatment did not affect OHRQoL very much.
Besides, a considerable percent of oral sign and symptoms, such as xerostomia, taste change and malodor were observed in these patients which is in agreement with other previous studies. ${ }^{33.35,36}$ Due to the increased rate of CRF patients that are under hemodialysis during the past few years, it is important to determine the effect of CRF on oral health and the effect of oral health on their QoL. Dental managements of patients with CRF are complicated because of the systemic consequences of this disease; however, using well supervised treatment protocols may provide reliable and effective clinical treatment. ${ }^{2}$

According to the current study, diabetes was the main cause of CRF in $37.2 \%$ of patients, which was higher than other studies. ${ }^{37,38}$ Malodor was presented in $40 \%$ of the individuals in this study, however, the results of Malekmakan et al (Iran) ${ }^{39}$ was $31 \%$ and Souza et al (Brazil) ${ }^{40}$ was $55 \%$. The presents of malodor was significantly related to increased levels of BUN in the patients. High blood urea concentration is one of the important causes of malodor. Other reasons are poor oral hygiene, dry mouth, the presence of urease splitting oral organisms, which metabolize urea (that is in high levels in these patients) and produce ammonia. ${ }^{33}$ Among the individuals, $35.2 \%$ complained of altered taste sensation, a finding similar to Malekmakan et al (33\%). ${ }^{39}$ Although, approximately half of the patients complained of dry mouth which can be caused by reduction of fluid intake, adverse side effects of drug therapy, increased levels of uremia in the saliva and mouth breathing. The prevalence

Table 3: Frequency (Percent) of subjects responding for GOHAl items based on calculations of ADD and SC method

\begin{tabular}{|c|c|c|c|c|c|c|c|c|c|}
\hline \multirow[t]{2}{*}{ Dimension } & \multirow{2}{*}{\multicolumn{2}{|c|}{ GOHAl items }} & \multicolumn{5}{|c|}{$A D D$} & \multicolumn{2}{|l|}{$S C$} \\
\hline & & & $\begin{array}{l}\text { Never } \\
n(\%)\end{array}$ & $\begin{array}{l}\text { Seldom } \\
n(\%)\end{array}$ & $\begin{array}{l}\text { Sometime } \\
n(\%)\end{array}$ & $\begin{array}{l}\text { Often } \\
n(\%)\end{array}$ & $\begin{array}{l}\text { Always } \\
n(\%)\end{array}$ & $\begin{array}{l}0 \\
n(\%)\end{array}$ & $\begin{array}{l}1 \\
n(\%)\end{array}$ \\
\hline & 1. & Limit the kinds of food & $36(24.8)$ & $33(22.8)$ & $28(19.3)$ & $35(24.1)$ & $13(9)$ & $97(66.9)$ & $48(33.1)$ \\
\hline \multirow[t]{3}{*}{ Physical function } & 2. & $\begin{array}{l}\text { Trouble biting or } \\
\text { chewing }\end{array}$ & $35(24.1)$ & $36(24.8)$ & $23(15.9)$ & $36(24.8)$ & $15(10.3)$ & $94(64.8)$ & $51(35.2)$ \\
\hline & 3. & $\begin{array}{l}\text { Uncomfortable to } \\
\text { swallow }\end{array}$ & $46(31.7)$ & $30(20.7)$ & $22(15.2)$ & $20(13.8)$ & $27(18.6)$ & $98(67.6)$ & $47(32.4)$ \\
\hline & 4. & Unable to speak clearly & $63(43.4)$ & $30(20.7)$ & $37(25.5)$ & $14(9.7)$ & $1(0.7)$ & $130(89.7)$ & $15(10.3)$ \\
\hline \multirow[t]{3}{*}{ Pain and discomfort } & 5. & Discomfort when eating & $18(12.4)$ & $59(40.7)$ & $27(18.6)$ & $30(20.7)$ & $11(7.6)$ & $104(71.7)$ & $41(28.3)$ \\
\hline & 8. & $\begin{array}{l}\text { Use medication to } \\
\text { relieve pain }\end{array}$ & $61(42.1)$ & $44(30.3)$ & $38(26.2)$ & $2(1.4)$ & $0(0)$ & $143(98.6)$ & $2(1.4)$ \\
\hline & 12. & $\begin{array}{l}\text { Sensitive to hot, or cold } \\
\text { or sweet foods }\end{array}$ & $76(52.4)$ & $35(24.1)$ & $20(13.8)$ & $12(8.3)$ & $2(1.4)$ & $131(90.3)$ & $14(9.7)$ \\
\hline \multirow[t]{5}{*}{ Psychological function } & 6. & $\begin{array}{l}\text { Limit the contact with } \\
\text { people }\end{array}$ & $69(47.6)$ & $42(29)$ & $30(20.7)$ & $4(2.8)$ & $0(0)$ & $141(97.2)$ & $4(2.8)$ \\
\hline & 7. & $\begin{array}{l}\text { Unhappy with } \\
\text { appearance }\end{array}$ & $14(9.7)$ & $40(27.6)$ & $33(22.8)$ & $33(22.8)$ & $25(17.2)$ & $87(60.0)$ & $58(40.0)$ \\
\hline & 9. & $\begin{array}{l}\text { Worried about teeth, } \\
\text { gums or dentures }\end{array}$ & $15(10.3)$ & $38(26.2)$ & $48(33.1)$ & $31(21.4)$ & $13(9)$ & $101(69.7)$ & $44(30.3)$ \\
\hline & & $\begin{array}{l}\text { Self-conscious of teeth, } \\
\text { gum or dentures }\end{array}$ & $36(24.8)$ & $44(30.3)$ & $40(27.6)$ & $24(16.6)$ & $1(0.7)$ & $120(82.8)$ & $25(17.2)$ \\
\hline & 11. & $\begin{array}{l}\text { Uncomfortable eating in } \\
\text { front of others }\end{array}$ & $38(26.2)$ & $40(27.6)$ & $47(32.3)$ & $17(11.7)$ & $3(2.1)$ & $125(86.2)$ & $20(13.8)$ \\
\hline
\end{tabular}

GOHAl indicates general oral health assessment index; ADD: additive; SC: simple count 
Oral Health-related Quality of Life and Periodontal and Dental Health Status in Iranian Hemodialysis Patients

Table 4: Frequency (Percent) of subjects responding for OHIP-14 items based on calculations of ADD and SC method

\begin{tabular}{|c|c|c|c|c|c|c|c|c|c|}
\hline \multirow[t]{2}{*}{ Dimensions } & \multirow{2}{*}{\multicolumn{2}{|c|}{ OHIP-14 items }} & \multicolumn{5}{|c|}{$A D D$} & \multicolumn{2}{|c|}{ SC } \\
\hline & & & $\begin{array}{l}\text { Never } \\
n(\%)\end{array}$ & $\begin{array}{l}\text { Seldom } \\
n(\%)\end{array}$ & $\begin{array}{l}\text { Sometime } \\
n(\%)\end{array}$ & $\begin{array}{l}\text { Often } \\
n(\%)\end{array}$ & $\begin{array}{l}\text { Very often } \\
n(\%)\end{array}$ & $\begin{array}{l}0 \\
n(\%)\end{array}$ & $\begin{array}{l}1 \\
n(\%)\end{array}$ \\
\hline \multirow[t]{2}{*}{$\begin{array}{l}\text { Functional } \\
\text { limitation }\end{array}$} & 1. & $\begin{array}{l}\text { Trouble pronouncing } \\
\text { words }\end{array}$ & $77(53.1)$ & $30(20.7)$ & $30(20.7)$ & $7(4.8)$ & $1(0.7)$ & $137(94.5)$ & $8(5.5)$ \\
\hline & 2. & Sense of taste worse & $47(32.4)$ & $38(26.2)$ & $33(22.8)$ & $19(13.1)$ & $8(5.5)$ & $118(81.4)$ & $27(18.6)$ \\
\hline \multirow[t]{2}{*}{ Physical pain } & 3. & $\begin{array}{l}\text { Painful aching in } \\
\text { mouth }\end{array}$ & $25(17.2)$ & $54(37.2)$ & $53(36.6)$ & $9(6.2)$ & $4(2.8)$ & $132(91.0)$ & $13(9.0)$ \\
\hline & 4. & Uncomfortable to eat & $27(18.6)$ & $32(22.1)$ & $55(37.9)$ & $24(16.6)$ & $7(4.8)$ & $114(78.6)$ & $31(21.4)$ \\
\hline \multirow{2}{*}{$\begin{array}{l}\text { Psychological } \\
\text { discomfort }\end{array}$} & 5. & Self-conscious & $38(26.2)$ & $40(27.6)$ & $46(31.7)$ & $17(11.7)$ & $4(2.8)$ & $124(85.5)$ & $21(14.5)$ \\
\hline & 6. & Felt tense & $42(29.0)$ & $34(23.4)$ & $43(29.7)$ & $22(15.2)$ & $4(2.8)$ & $119(82.1)$ & $26(17.9)$ \\
\hline \multirow{2}{*}{$\begin{array}{l}\text { Physical } \\
\text { disability }\end{array}$} & 7. & Unsatisfactory Diet & $34(23.4)$ & $35(24.1)$ & $41(28.3)$ & $25(17.2)$ & $10(6.9)$ & $110(75.9)$ & $35(24.1)$ \\
\hline & 8. & Had to interrupt meals & $36(24.8)$ & $30(20.7)$ & $46(31.7)$ & $22(15.2)$ & $11(7.6)$ & $112(77.2)$ & $33(22.8)$ \\
\hline \multirow{2}{*}{$\begin{array}{l}\text { Psychological } \\
\text { disability }\end{array}$} & 9. & Difficult to relax & $40(27.6)$ & $29(20.0)$ & $50(34.5)$ & $17(11.7)$ & $9(6.2)$ & $119(82.1)$ & $26(17.9)$ \\
\hline & 10. & Embarrassed & $61(42.1)$ & $48(33.1)$ & $28(19.3)$ & $5(3.4)$ & $3(2.1)$ & $137(94.5)$ & $8(5.5)$ \\
\hline \multirow[t]{2}{*}{ Social disability } & 11. & Irritability with others & $65(44.8)$ & $36(24.8)$ & $31(21.4)$ & $11(7.6)$ & $2(1.4)$ & $132(91.0)$ & $13(9.0)$ \\
\hline & 12. & $\begin{array}{l}\text { Difficulty doing usual } \\
\text { jobs }\end{array}$ & $63(43.4)$ & $35(24.1)$ & $35(24.1)$ & $9(6.2)$ & $3(2.1)$ & $133(91.7)$ & $12(8.3)$ \\
\hline \multirow[t]{2}{*}{ Handicap } & 13. & Felt life less satisfying & $67(46.2)$ & $31(21.4)$ & $30(20.7)$ & $14(9.7)$ & $3(2.1)$ & $128(88.3)$ & $17(11.7)$ \\
\hline & 14. & $\begin{array}{l}\text { Totally unable to } \\
\text { function }\end{array}$ & $73(50.3)$ & $35(24.1)$ & $29(20.0)$ & $7(4.8)$ & $1(0.7)$ & $137(94.5)$ & $8(5.5)$ \\
\hline
\end{tabular}

OHIP-14 indicates oral health impact profile-14; ADD: Additive; SC: Simple count

Table 5: The mean scores of OHRQoL according to sex, age group, duration of dialysis, OHI-S, self-rating of oral health, dry mouth, taste change, halitosis, diabetes and p-values

\begin{tabular}{|c|c|c|c|c|c|c|c|c|c|}
\hline \multirow[t]{2}{*}{ Variables } & & \multicolumn{2}{|c|}{$\begin{array}{c}\text { OHIP-14 } \\
(\text { mean } \pm S D)\end{array}$} & \multicolumn{2}{|c|}{$p$-value } & \multicolumn{2}{|c|}{$\begin{array}{c}\text { GOHAl } \\
(\text { mean } \pm S D)\end{array}$} & \multicolumn{2}{|c|}{$p$-value } \\
\hline & & $A D D$ & SC & $A D D$ & SC & $A D D$ & SC & $A D D$ & SC \\
\hline \multirow[t]{2}{*}{ Sex $^{+}$} & Male $(n=77)$ & $30.55 \pm 11.37$ & $1.4 \pm 2.8$ & 0.62 & 0.10 & $28.83 \pm 8.29$ & $2.4 \pm 2.3$ & 0.91 & 0.724 \\
\hline & Female $(n=68)$ & $32.19 \pm 13.76$ & $2.5 \pm 3.9$ & & & $29.34 \pm 8.77$ & $2.7 \pm 2.7$ & & \\
\hline \multirow[t]{3}{*}{ Age $^{\#}$} & $<40$ years $(n=26)$ & $26.69 \pm 10.05$ & $0.8 \pm 1.9$ & & & $26.03 \pm 6.23$ & $1.7 \pm 1.5$ & & \\
\hline & $40-59$ years $(n=45)$ & $31.22 \pm 12.70$ & $1.9 \pm 3.2$ & 0.09 & 0.15 & $29.36 \pm 8.28$ & $2.6 \pm 2.2$ & 0.12 & 0.15 \\
\hline & $\geq 60$ years $(n=74)$ & $33.00 \pm 12.94$ & $2.3 \pm 3.8$ & & & $29.96 \pm 9.15$ & $2.8 \pm 2.9$ & & \\
\hline Hemodialysis & $<24$ month $(n=47)$ & $29.85 \pm 11.08$ & $1.5 \pm 2.5$ & 0.45 & 0.94 & $28.00 \pm 8.16$ & $2.3 \pm 2.3$ & 0.30 & 0.57 \\
\hline Duration $^{+}$ & $\geq 24$ month $(n=98)$ & $32.02 \pm 13.17$ & $2.1 \pm 3.7$ & & & $29.58 \pm 8.65$ & $2.7 \pm 2.6$ & & \\
\hline \multirow[t]{3}{*}{$\mathrm{OHI}-\mathrm{S}^{+}$} & Good $(n=7)$ & $20.86 \pm 6.97$ & $0.0 \pm 0.0$ & & & $22.00 \pm 4.47$ & $1.0 \pm 0.8$ & & \\
\hline & Fair $(n=25)$ & $30.44 \pm 8.77$ & $1.0 \pm 2.1$ & 0.04 & 0.13 & $28.52 \pm 5.79$ & $2.0 \pm 1.7$ & 0.01 & 0.044 \\
\hline & Poor $(n=63)$ & $32.38 \pm 12.40$ & $2.0 \pm 3.4$ & & & $31.01 \pm 8.62$ & $3.0 \pm 2.6$ & & \\
\hline Self-rating & Good $(n=58)$ & $25.29 \pm 10.76$ & $0.8 \pm 2.4$ & & & $24.83 \pm 6.99$ & $1.5 \pm 1.8$ & & \\
\hline of oral & Fair $(n=49)$ & $31.53 \pm 10.58$ & $1.6 \pm 2.7$ & 0.001 & 0.001 & $29.45 \pm 7.51$ & $2.6 \pm 2.1$ & 0.001 & 0.001 \\
\hline health & Poor $(n=38)$ & $40.24 \pm 12.20$ & $4.1 \pm 4.4$ & & & $35.05 \pm 8.19$ & $4.1 \pm 3.1$ & & \\
\hline \multirow[t]{2}{*}{ Dry mouth ${ }^{+}$} & Present $(n=75)$ & $34.78 \pm 13.01$ & $2.9 \pm 4.0$ & 0.001 & 0.001 & $31.23 \pm 8.60$ & $3.3 \pm 2.7$ & 0.002 & 0.001 \\
\hline & Absent $(n=70)$ & $27.60 \pm 10.92$ & $0.9 \pm 2.1$ & & & $26.76 \pm 7.80$ & $1.8 \pm 2.0$ & & \\
\hline \multirow[t]{2}{*}{ Taste change $^{+}$} & Present $(n=51)$ & $36.25 \pm 13.30$ & $3.6 \pm 4.2$ & 0.001 & 0.001 & $31.69 \pm 9.09$ & $3.6 \pm 2.8$ & 0.012 & 0.001 \\
\hline & Absent $(n=94)$ & $28.64 \pm 11.29$ & $1.0 \pm 2.4$ & & & $27.65 \pm 7.85$ & $2.0 \pm 2.1$ & & \\
\hline \multirow[t]{2}{*}{ Halitosis $^{+}$} & Present $(n=58)$ & $35.48 \pm 12.97$ & $3.2 \pm 4.1$ & 0.001 & 0.001 & $30.50 \pm 9.02$ & $3.1 \pm 2.7$ & 0.15 & 0.040 \\
\hline & Absent $(n=87)$ & $28.54 \pm 11.49$ & $1.1 \pm 2.5$ & & & $28.11 \pm 8.04$ & $2.2 \pm 2.2$ & & \\
\hline Diabetic main & Yes $(n=54)$ & $34.87 \pm 14.56$ & $3.1 \pm 4.1$ & 0.020 & 0.004 & $30.52 \pm 9.60$ & $2.9 \pm 2.7$ & 0.16 & 0.363 \\
\hline cause $^{+}$ & No $(n=91)$ & $20.20 \pm 10.69$ & $1.3 \pm 2.7$ & & & $28.21 \pm 7.69$ & $2.3 \pm 2.3$ & & \\
\hline \multirow[t]{2}{*}{ Dentition $^{+}$} & Dentate $(n=95)$ & $31.27 \pm 11.56$ & $1.7 \pm 3.1$ & 0.722 & 0.19 & $29.77 \pm 8.04$ & $2.6 \pm 2.4$ & 0.19 & 0.33 \\
\hline & Edentulous $(n=50)$ & $31.40 \pm 14.32$ & $2.4 \pm 3.8$ & & & $27.74 \pm 9.25$ & $2.5 \pm 2.7$ & & \\
\hline
\end{tabular}

${ }^{+} p$-value was driven from Wilcoxon; ${ }^{*} p$-value was driven from Kruskal-Wallis test in analysis of variances (ANOVA); OHIP-14 indicates oral health impact profile-14; GOHAl: General oral health assessment index; ADD: additive; SC: Simple count and OHI-S: Simplified oral hygiene index 
Table 6: Pearson correlation coefficient between dental and periodontal indexes and OHRQoL outcomes according to calculations of ADD and SC method

\begin{tabular}{|c|c|c|c|c|c|c|c|c|}
\hline \multirow{3}{*}{$\begin{array}{l}\text { Periodontal and dental } \\
\text { parameters }\end{array}$} & \multicolumn{4}{|c|}{ OHIP-14 } & \multicolumn{4}{|c|}{ GOHAI } \\
\hline & \multicolumn{2}{|c|}{$A D D$} & \multicolumn{2}{|c|}{$S C$} & \multicolumn{2}{|c|}{$A D D$} & \multicolumn{2}{|c|}{ SC } \\
\hline & $r$ & $p$-value & $r$ & $p$-value & $r$ & $p$-value & $r$ & $p$-value \\
\hline Plaque index score & 0.374 & 0.001 & 0.294 & 0.004 & 0.408 & 0.001 & 0.345 & 0.001 \\
\hline $\begin{array}{l}\text { Periodontal disease index } \\
\text { score }\end{array}$ & 0.40 & 0.001 & 0.262 & 0.01 & 0.449 & 0.001 & 0.343 & 0.001 \\
\hline Decay missing filling tooth & 0.34 & 0.001 & 0.215 & 0.04 & 0.401 & 0.001 & 0.329 & 0.001 \\
\hline
\end{tabular}

OHIP-14 indicates oral health impact profile-14; GOHAl: General oral health assessment index; ADD: Additive; SC: Simple count

of self-reported dry mouth complaints was 40.0 to 67.7 in the previous studies. ${ }^{37.39,41}$ Chewing gum or using saliva substitutes are some recommended strategies for alleviating xerostomia. ${ }^{42}$ It should be noticed that xerostomia could lead to higher accumulation of plaque and caries risk, so it is necessary for the patients to be monitored by oral health professionals continuously. But in the reality, we do not have regular follow-up dental visits. In our study, the last dental visit of $77.9 \%$ of patients was more than 2 years from the time the examination was done. This finding is in agreement with Cunha et al findings which the last dental visit was more than 2 years in $70 \%$ of patients. ${ }^{37}$ The reason might be large amount of expenses for drugs and the treatment of their life-threatening medical problems that causes ignorance toward oral health and physical health will be in priority for these patients. Also, high costs for dental treatment, not being capable for paying the treatment cost, lack of awareness, motivation and negligence toward oral health leads to the fact that the patients do not attend to dentists unless when an emergency treatment is needed. Dumitrescu et al demonstrated that the reason for not visiting the dentist was dental anxiety in $51.6 \%$ of the participants and financial problems in $37.3 \%{ }^{43}$

The mean DMFT in this study was almost similar to the results of the previous studies in Iran. ${ }^{39-41}$ but it was higher than those reported in Germany and Brazil. ${ }^{37,38}$ Even though in another investigation in Jordan, the mean DMFT was much lower than our findings. ${ }^{25}$ The low rate of caries is thought to be related to protective and antibacterial effect of high urea concentrations or increased calculus. ${ }^{33,35}$ According to our finding there was no relationship between DMFT index and hemodialysis duration. This fact has been confirmed by Malekmakan et a ${ }^{39}$ and Cengiz et al. ${ }^{44}$ However, Sekiguchi et al indicated that DMFT index was higher in patients who undergone hemodialysis $>3$ years in compared with $<3$ years group. ${ }^{45}$

In the present investigation, there was no relation between the mean PLI and hemodialysis duration which is in agreement with Sekiguchi et $\mathrm{al}^{45}$ and AL-Wahadni and $\mathrm{AL}-\mathrm{Omari}^{25}$ results. Whereas, the results of some other studies demonstrated a positive relationship between PLI scores and time on dialysis. ${ }^{28.44}$ Results from the present study showed that the duration of renal hemodialysis had no effect on periodontal health of the individuals. This is in accordance with the result of some studies ${ }^{25,32,41,46}$ while it is different to some other investigations..$^{28,29,45}$ Conflicting result in different communities could be due to the effect of high $\mathrm{pH}$, the buffer capacity of saliva, changes in the salivary flow rate and individual and cultural issues.

In this study, more than $60 \%$ of the patients had a poor oral hygiene index, a similar finding was also reported by Bhatsange et al in India. ${ }^{47}$ In the present study, oral hygiene status was not associated with gender and hemodialysis duration of the patients, but it gets worst when the age is increased. The poor oral hygiene of these patients could be explained by the chronic nature of the renal disease, the patients are usually concerned about the irreversible condition of their kidneys and their life-threatening problem so, this leads to the situation that they neglect of having preventive treatments for other aspects of their health such as oral and dental health. The attitude toward oral hygiene was week among our study population that is in accord with those in other studies..$^{5,7,25,26,31-33}$ Besides, a majority of patients undergoing hemodialysis did not suffer only from their kidneys situations but also they had a complicated medical condition such as diabetes, hypertension, cardiovascular disease and increased bleeding tendency. These could all be possible risk factors for the poor oral health situation.

The mean OHIP-14 and GOHAI scores was lower than the expected score for each questionnaire (According to the range of the scores for the 2 questionnaires, the expected mean was 42 for OHIP-14 and 36 for GOHAI) which demonstrates an approximately good OHRQoL in these patients. These results are also demonstrated in Guzeldemir et al study. ${ }^{7}$ However, the number of patients in this study was more than Guzeldemir investigation.

According to the current study, oral complications and poor periodontal and dental condition are not a major concern in the most of this group of patients and attention to oral health is not a priority for them but despite the low number of tooth and poor oral hygiene, they are satisfied of their oral and dental conditions. This is because of the fact that 
the systemic difficulties are their main concern. Although these patients have a poor oral health, high number of decay and missed teeth, increased plaque accumulations and periodontal disease but the scores of the two questionnaires were approximately in a good level. However, the end stage renal disease and the hemodialysis treatment affects the patients QoL ${ }^{48,49}$ but OHRQoL is not affected very much. In fact, although our patients had a poor oral health, they are satisfied from their mastication, speech and swallowing.

If there were information from the individuals oral health and hygiene status right from the beginning of hemodialysis therapy, by comparing the results prior to hemodialysis with the results after that, the actual severity of oral hygiene and OHRQoL will be possible to detect. A prospective study is recommended for assessing the effect of hemodialysis on the patients OHRQoL, including a control group (with age and sex matched participants without systemic disease and with similar levels of oral hygiene and dental and periodontal status) for future investigations.

\section{CONCLUSION}

Although our study indicated that hemodialysis patients have poor oral hygiene and periodontal status, weak attitudes and negligence toward oral health, and they do not visit the dentists on regular basis but they were satisfied of their oral health conditions and their OHRQoL was approximately good. It is necessary for the dental community's and the dialysis center staff to keep the patients under regular follow-up and preventive dental care and there should be communications between nephrologists and oral healthcare professionals in order to promote the patients oral health status.

\section{CLINICAL SIGNIFICANCE}

The findings high light the need of comprehensive oral examinations including periodontal therapy, restorative treatment, preventive dental treatment and follow-up care in the hemodialysis patients.

\section{ACKNOWLEDGMENTS}

The authors would like to thank the manager, staff and the nurses of Hemodialysis Center of Shahid Beheshti Hospital, for their assistance in our examination of patients and data collection.

\section{REFERENCES}

1. Snyder S, Pendergraph B. Detection and evaluation of chronic kidney disease. Am Fam Physician 2005 Nov 1;72(9):1723-1732.

2. Proctor R, Kumar N, Stein A, Moles D, Porter S. Oral and dental aspects of chronic renal failure. J Dent Res 2005 Mar; 84(3): 199-208.
3. Caskey FJ, Schober-Halstenberg HJ, Roderick PJ, Edenharter G, Ansell D, Frei U, Feest TG. Exploring the differences in epidemiology of treated ESRD between Germany and England and Wales. Am J Kidney Dis 2006 Mar;47(3):445-454.

4. Gudapati A, Ahmed P, Rada R. Dental management of patients with renal failure. Gen Dent 2002 Nov-Dec;50(6):508-510.

5. Gavaldá C, Bágan J, Scully C, Silvestre F, Milián M, Jiménez Y. Renal hemodialysis patients: oral, salivary, dental and periodontal findings in 105 adult cases. Oral Dis 1999 Oct;5(4): 299-302.

6. Sobrado Marinho JS, Tomas Carmona I, Loureiro A, Limeres Posse J, García Caballero L, Diz Dios P. Oral health status in patients with moderate-severe and terminal renal failure. Med Oral Patol Cir Bucal 2007 Aug 1;12(4):305-310.

7. Guzeldemir E, Toygar HU, Tasdelen B, Torun D. Oral healthrelated quality of life and periodontal health status in patients undergoing hemodialysis. J Am Dent Assoc 2009 Oct; 140(10): 1283-1293.

8. Hebling E, Pereira AC. Oral health-related quality of life: a critical appraisal of assessment tools used in elderly people. Gerodontology 2007 Sep;24(3):151-161.

9. Slade GD, Spencer AJ. Development and evaluation of the oral health impact profile. Community Dent Health 1994 Mar; 11(1):3-11.

10. Slade GD. Derivation and validation of short-form oral health impact profile. Community Dent Oral Epidemiol 1997 Aug; 25(4):284-290.

11. Atchison KA, Dolan TA. Development of the geriatric oral health assessment index. J Dent Educ 1990 Nov; 54(11):680-687.

12. Tubert-Jeannin S, Riordan PJ, Morel-Papernot A, Porcheray S, Saby-Collet S. Validation of an oral health quality of life index (GOHAI) in France. Community Dent Oral Epidemiol 2003 Aug;31(4):275-284.

13. Naito M, Suzukamo Y, Nakayama T, Hamajima N, Fukuhara S. Linguistic adaptation and validation of the general oral health assessment index (GOHAI) in an elderly Japanese population. J Public Health Dent 2006 Fall;66(4):273-275.

14. Hassel AJ, Rolko C, Koke U, Leisen J, Rammelsberg P. A German version of the GOHAI. Community Dent Oral Epidemiol 2008 Feb;36(1):34-42.

15. Einarson S, Warnberg Gerdin E, Hugoson A. Oral health impact on quality of life in an adult Swedish population. Acta Odontol Scand 2009;67(2):85-93.

16. A-Dan W, Jun-Qi L. Factors associated with the oral healthrelated quality of life in elderly persons in dental clinic: validation of a Mandarin Chinese version of GOHAI. Gerodontology 2011 Sep;28(3):184-191.

17. Motallebnezhad M, Hadian H, Mehdizadeh SH, Hajiahmadi M. Validity and reliability of persian version of oral health impact profile 14 (OHIP-14). Caspian J Intern Med 2011;2(4):314-320.

18. Motallebnezhad M, Mottaghi K, Mehdizade SH, Alaeddini F, Bijani A. Reliability and validity of persian version of the general oral health assessment index (GOHAI). Caspian J Dent Res 2013 Mar;1(2):8-17.

19. Ergül S, Akar GC. Reliability and validity of the Geriatric Oral Health Assessment Index in Tukey. J Gerontol Nurs 2008 Sep; 34(9):33-39.

20. Nakhjavani YB, Bayramy A. The dental and oral status of children with chronic renal failure. J Indian Soc Pedod Prev Dent 2007 Mar;25(1):7-9.

21. Wolff A, Stark H, Binderman I, Eisenstein B, Drukker A. The dental status of children with chronic renal Failure. Int J Pediatr Nephrol 1985 Apr-Jun;6(2):127-132. 
22. Al Nowaiser A, Roberts GJ, Trompeter RS, Wilson M, Luces VS. Oral health in children with chronic renal failure. Pediatr Nephrol 2003 Jan;18(1):39-45.

23. Peterson S, Woodhead J, Crall J. Caries resistance in children with chronic renal failure: Plaque $\mathrm{pH}$, salivary $\mathrm{pH}$ and salivary composition. Pediatr Res 1985 Aug;19(8):796-799.

24. Davidovich E, SchwarzZ, Davidovitch M,Eidelman E, Bimstein E. Oral findings and periodontal status in children, adolescents and young adults suffering from renal failure. J Clin Periodontol 2005 Oct;32(10):1076-1082.

25. Al-Wahadni A, Al-Omari MA. Dental diseases in a Jordanian population on renal dialysis. Quintessence Int 2003 May; 34(5):343-347.

26. Bots C, Poorterman J, Brand H, Kalsbeek H, Van Amerongen BM, Veerman EC, Nieuw Amerongen AV. The oral health status of dentate patients with chronic renal failure undergoing dialysis therapy. Oral Dis 2006 Mar;12(2):176-180.

27. Chen LP, Chiang CK, Chan CP, Hung KY, Huang CS. Does periodontitis reflect inflammation and malnutrition status in hemodialysis patients? Am J Kidney Dis 2006 May;47(5):815-822.

28. Jenabian N, Ghazi Mirsaeed AM, Ehsani H, Kiakojori A. Periodontal status of patient's underwent hemodialysis therapy. Caspian J Med 2013 Spring;4(2):658-661.

29. Mortazavi H, Abdossamadi HR, Vahedi M, Abdollahzadeh SH, Firoozemoghadam I, Khodadoustan A. Kheyri A. Evaluation of the dental and periodontal status of haemodialysis subjects and its comparison with that of healthy people. Sci J Hamedan Univ Med Sci 2010;17(4):10-16.

30. Hamissi J, Porsamimi J, Naseh MR, Mosalaei S. Oral hygiene and periodontal status of hemodialyzed patients with chronic renal failure in Qazvin, Iran. East Afr J Public Health 2009 Apr; 6(1):108-111.

31. Bayraktar G, Kurtulus I, Duraduryan A, Cintan S, Kazancioglu R, Yildiz A, Bural C, Bozfakioglu S, Besler M, Trablus S, et al. Dental and periodontal findings in hemodialysis patients. Oral Dis 2007 Jul;13(4):393-397.

32. Naugle K, Darby ML, Bauman DB, Lineberger LT, Powers $\mathrm{R}$. The oral health status of individuals on renal dialysis. Ann Periodontal 1998 Jul;3(1):197-205.

33. Klassen JT, Krasko BM. The dental health status of dialysis patients. J Can Dent Assoc 2002 Jan;68(1):34-38.

34. World Health Organization. Oral health surveys. Basic methods. 4th ed. Geneva: WHO 1997.

35. Ertuğrul F, Elbek-Cubukçu C, Sabah E, Mir S. The oral health status of children undergoing hemodialysis treatment. Turk $\mathrm{J}$ Pediatr 2003 Apr-Jun;45(2):108-113.

36. Chuang SF, Sung JM, Kuo SC, Huang JJ, Lee SY. Oral and dental manifestations in diabetic and nondiabetic uremic patients receiving hemodialysis. Oral Surg Oral Med Oral Pathol Oral Radiol Endod 2005 Jun;99(6):689-695.

37. Cunha FL, Tagliaferro EP, Pereira AC, Meneghim MC, Hebling E. Oral health of Brazilian population on renel dialysis. Spec Care Dentist 2007 Nov-Dec;27(6):227-231.

38. Ziebolz D, Fischer P, Hornecker E, Mausberg RF. Oral health of hemodialysis patients: a cross-sectional study at two German dialysis centers. Hemodial Int 2012 Jan;16(1):69-75.

39. Malekmakan L, Haghpanah S, Pakfetrat M, Ebrahimic Z, Hasanlic E. Oral health status in Iranian hemodialysis patients. Indian J Nephrol 2011 Oct;21(4):235-238.

40. Souza CM, Braosi AP, Luczyszyn SM, Casagrande RW, PecoitsFiho R, Riella MC, Ignácio SA, Trevilatto PC. Oral health in Brazilian patients with chronic renal disease. Rev Med Chil 2008 Jun;136(6):741-746.

41. Chamani G, Zarei MR, Radvar M, Rashidfarrokhi F, Razazpour F. Oral health status of dialysis patients based on their renal dialysis history in Kerman, Iran. Oral Health Prev Dent 2009; 7(3):269-275.

42. Bots CP, Brand HS, Veerman EC, Valentijn-Benz M, Van Amerongen BM, Nieuw Amerongen AV, Valentijn RM, Vos PF, Bijlsma JA, Bezemer PD, et al. The management of xerostomia in patients on haemodialysis: comparision of artificial saliva and chewing gum. Palliat Med 2005 Apr;19(3):202-207.

43. Dumitrescu AL, Gârneaţă L, Guzun O. Anxiety, stress, depression, oral health status and behaviours in Romanian hemodialysis patients. Rom J Intern Med 2009;47(2): 161-168.

44. Cengiz MI, Sümer P, Cengiz S, Yavuz U. The effect of the duration of the dialysis in hemodialysis patients on dental and periodontal findings. Oral Dis $2009 \mathrm{Jul} ; 15(5): 336-341$.

45. Sekiguchi RT, Pannuti CM, Silva HT Jr, Medina-Pestana JO, Romito GA. Decrease in oral health may be associated with length of time since beginning dialysis. Spec Care Dentist 2012 Jan-Feb;32(1):6-10.

46. Torkzaban P, Arabi R, Kadkhodazadeh M, Moradi J, Khoshhal M. Periodontal status in patients undergoing hemodialysis. Dent $\mathbf{J}$ Hamedan 2009;1:7-10.

47. Bhatsange A, Patil SR. Assessment of periodontal health status in patients undergoing renal dialysis: a descriptive, cross-sectional study. J Indian Soc Periodontol 2012 Jan;16(1):37-42.

48. Griffin KW, Wadhwa NK, Friend R, Suh H, Howell N, Cabralda T, Jao E, Hatchett L, Eitel PE. Comparison of quality of life in haemodialysis and peritoneal dialysis patients. Adv Perit Dial 1994;10:104-108.

49. Anees M, Hameed F, Mumtaz A, Ibrahim M, Saeed Khan MN. Dialysis-related factors affecting quality of life in patients on hemodialysis. Iran J kidney Dis 2011 Jan;5(1):9-14. 